\title{
ESCRITURAS ILEGÍVEIS E COMUNIDADE LITERÁRIA
}

\author{
ILLEGIBLE WRITINGS AND THE LITERARY COMMUNITY
}

Ana Cecilia Olmos

$\mathrm{USP} / \mathrm{CNPq}$

São Paulo, Brasil

\begin{abstract}
Resumo
As escrituras de Héctor Libertella e Diamela Eltit operam como máquinas de corrosão da linguagem, desestabilizando os sentidos cristalizados do literário que remetem aos mandatos de representaçáo do nacional ou continental. Trata-se de escrituras que, ao apelar ao traço singular e único dos idioletos, questionam todo regime de representação e renunciam à nitidez tranquilizadora do comunicável no seio da comunidade. Porém, esses autores também exploram o ensaio como forma discursiva que oferece uma condição de diálogo que permite restabelecer esses vínculos com o comum, sem deixar de problematizá-los. Por meio do ensaio, esses escritores buscam intervir criticamente no debate acerca da representação do latino-americano como variável determinante da literatura. Esse trabalho propôe indagar qual é a relação que se estabelece entre a singularidade expressiva dessas escrituras e o comum que o ensaio convoca.
\end{abstract}

Palavras-chave: Ensaio; Comunidade; Libertella; Eltit.

\section{Resumen}

Las escrituras de Héctor Libertella y Diamela Eltit operan como máquinas de corrosión del lenguaje, desestabilizando los sentidos cristalizados de lo literario que remiten a los mandatos de representación de lo nacional o continental. Se trata de escrituras que, al apelar al trazo singular y único de los idiolectos, cuestionan todo régimen de representación y renuncian a la nitidez tranquilizadora de lo comunicable en el seno de la comunidad. Pero estos autores también exploran el ensayo como forma discursiva que ofrece una condición de diálogo que permite restablecer esos vínculos con lo común, sin dejar de problematizarlos. A través del ensayo, estos escritores buscan intervenir críticamente en el debate acerca de la representación de lo local como variable determinante de la literatura. Este trabajo propone indagar cuál

\section{Abstract}

Héctor Libertella and Diamela Eltit's writings, which work as machines of language corrosion, destabilize the settled meanings of the literary phenomenon in respect to the standard representation of the national or the continental. As these compositions resort to the idiolects' particular and unique trait, they question the whole representation system, renouncing the comforting clearness of what can be communicable in the heart of the community. Nevertheless, these authors also employ the essay as the discursive form that offers a condition of dialogue, which allows them to reconnect with the ordinary as they continually examine it. By writing essays, these authors seek to intervene critically in the debate on the representation of Latin America as a decisive variable in literature. The present paper proposes to question the nature of the 
es la relación que se establece entre la singularidad expresiva de esas escrituras y lo común que el ensayo convoca.

Palabras clave: Ensayo; Comunidad; Libertella; Eltit. relation established between the expressive singularity of those writings and the ordinary activated by the essay.

Keywords: Essay; Community; Libertella; Eltit.

Em "Las sacras arcas del español", Severo Sarduy nos provoca com a seguinte pergunta:

¿Qué sucedería si nos hablaran en un idioma y entendiéramos en otro, si lo que nos entra por una oreja nos saliera por la otra pero fragmentado, invertido, reducido a la alquimia de sus letras o a su anagrama? [...] detrás del asegurador "No te mata" podría ocultarse la noche enloquecida - notte matta -; todo hay uno sería acompañado por su abstinencia; y cada sorpresa significaría la prisión de una pobre monja - sor presa -. El emblema barroco de este universo ya no delirante sino dalirante no sería otro que un onagro sobre un órgano, incongruente coincidencia, como la de un paraguas sobre una mesa de disección, pero cuyo soporte es un juego de letras, una recombinación de letras: la vida es un crucigrama feroz. (SARDUY, 2000: 124)

Recupero a provocação barroca de Sarduy para pôr em cena escrituras que na América Latina operam como máquinas de desmantelamento da língua que desordenam "las sacras arcas del español". Escrituras que realizam um trabalho de corrosão da linguagem, de seus sentidos coagulados e de suas pautas de legibilidade. Escrituras que não transigem com a ordem tranquilizadora do sentido único e optam por radicalizar uma operação dessacralizadora da língua por meio da qual os autores inscrevem seu próprio idioleto, sua própria glossolalia, seu próprio jargão. Em síntese, escrituras que nas suas singularidades expressivas não fazem senão afirmar uma crítica radical da ordem do legível.

Ninguém duvidaria em reconhecer na escritura de Héctor Libertella uma dessas operaçóes extremas de desmoronamento da linguagem. Desde o final dos anos 1960, em cada uma de suas páginas, se abre uma palavra poética que aspira a se bastar a si mesma mediante a exacerbação de uma discursividade última e autônoma que apaga a voz de origem, descentra a subjetividade, prescinde de um destinatário e resiste à função referencial. Tenazmente intransitiva, essa palavra literária se apresenta à maneira de um hieróglifo que comporta no seu próprio traço a ideia de escritura. Com similar caráter revulsivo, a escritura de Diamela Eltit desliza uma palavra poética que desarticula a língua em uma operação radical de subversão do léxico, da sintaxe e do sentido, que libera a literatura de qualquer regime de representação. Basta lembrar seu primeiro romance, Lumpérica (1983), no qual a voz narrativa, como 
explica Gilles Deleuze (1997: 123): "efetua toda a potência de bifurcação e de variação, de heterogênese e de modulação própria da língua", inscrevendo nela uma dinâmica de perpétuo desequilíbrio que traz a um primeiro plano o exterior da linguagem. Trata-se, em ambos os casos, de escrituras sem código possível, que não remetem ao universal da linguagem, mas ao traço singular e único dos idioletos, que questionam todo regime de representação e renunciam, assim, à nitidez tranquilizadora do comunicável. Como se nos falassem em uma língua e entendêssemos em outra, parafraseando Sarduy, como se a literatura fosse um "crucigrama feroz".

\section{Idiorritmia e ensaio}

Ao tenderem para um uso assignificante da língua, as escrituras de Libertella e Eltit desmantelam os dispositivos que ordenam o discurso literário em função de perspectivas históricas desenvolvimentistas, representaçôes identitárias, hierarquias culturais e taxonomias discursivas e estéticas. Nesse sentido, a ilegibilidade como política da literatura expele esses autores para as margens geradas por toda escritura que se funda no mundo do linguisticamente particular. Suas ficções, em especial, podem ser pensadas nesses termos. Não obstante, esses autores também frequentam o ensaio. Uma forma discursiva que, ao desenhar uma deriva exploratória da subjetividade, resiste às fórmulas disciplinadas da comunicabilidade, mas não deixa de oferecer ao leitor uma interpretação inteligível do mundo que o convoca ao diálogo. ${ }^{2}$ Proponho pensar, nesta oportunidade, o lugar do ensaio nas escritu-

\footnotetext{
${ }^{1} \mathrm{Na}$ imagem barroca da escritura que propóe o ensaio de Sarduy - uma introduçấo à sua leitura de Larva de Julián Ríos -, ecoa a ideia deleuziana da literatura como a invençáo de um uso menor da língua na qual alguns escritores se expressam (Kafka, Beckett, Artaud, Roussel). Deleuze explica que, nesses casos, os escritores "minoran essa língua, como em música, onde o modo menor designa combinaçôes dinâmicas em perpétuo desequilíbrio. São grandes à força de minorar: eles fazem a língua fugir, fazem-na deslizar numa linha de feitiçaria e não param de desequilibrá-la, de fazê-la bifurcar e variar em cada um de seus termos, segundo uma incessante modulação. Isso excede as possibilidades da fala e atinge o poder da língua e mesmo da linguagem. Equivale a dizer que um grande escritor sempre se encontra como um estrangeiro na língua em que se exprime, mesmo quando é a sua língua natal. No limite, ele toma suas forças numa minoria muda desconhecida, que só a ele pertence. É um estrangeiro em sua própria língua: não mistura outra língua à sua, e sim talha na sua língua uma língua estrangeira que não preexiste" (DELEUZE, 1997: 124-125).
}

${ }^{2}$ Recupero aqui a distinção que Horacio González estabelece entre comunicabilidade e inteligibilidade ao refletir sobre o ensaio como gênero discursivo nas ciências sociais. Ele sugere que é necessário separar ambos os termos: "Con la primera, aceptamos fácilmente las sonoridades ya preparadas. Nuestras escrituras serán adaptativas, adosadoras, repitientes. No se crea que no hay placer en ello. Pero generalmente no es a lo que aspiran sus cultores. Con la segunda, aceptamos que lo que se entiende de un texto no es lo que éste ofrece en su primera lectura, en su primera estribación, en sus morisquetas didácticas, o en sus trazos autoevidentes. [...] preferimos nosotros una incomunicabilidad sin comunicación. Esto último significa que lo que hay que 'construir' no es necesariamente el dato, sino nuestra propia comprensión impaciente de un texto que se complace en atravesar sus propios 
ras de Libertella e Eltit. Não pretendo compará-las, dado que a própria ideia de ilegibilidade impede isso (lembremos que a ilegibilidade não é uma figura plena, descritível, e sim uma posição crítica ante a ordem do legível), também não tenciono assinalar um paradoxo entre a singularidade desagregadora dessas escrituras e a pauta dialógica do ensaio, senão indagar que vínculos com a comunidade buscam estabelecer essas práticas literárias, que resistem à transparência do comunicável, quando exploram a forma do ensaio.

A noção de idiorritmia que Barthes propóe em Como viver junto é o ponto de partida dessa indagaçáa. ${ }^{3}$ Como ele explica, a idiorritmia se referia ao direito de certos indivíduos ou de pequenos grupos de indivíduos de viver à parte no seio da comunidade. $\mathrm{O}$ anacoreta é a figura que ele convoca como exemplo dessa fantasia de vida que se sustenta na aporia da "partilha das distâncias": querer viver só e viver junto ao mesmo tempo. Barthes lembra que a etimologia do termo idiorritmia náo remete ao corte compassado com o qual habitualmente relacionamos a ideia de ritmo, e sim a elementos fluidos, formas modificáveis, configuraçóes não estáveis, vale dizer, sem fixação nem necessidade natural, tal como o drapeado da roupa, as mudanças de humor e o traçado da letra. Individual por definição, a idiorritmia delineia um movimento intersticial, provoca a fuga do código, delimita uma posição exorbitante, que resiste tanto ao isolamento como à integraçáo, e abre o espaço de uma margem ameaçadora que recusa a incorporação a uma estrutura de poder. Todo regime de idiorritmia instaura, portanto, uma tensão entre a voz da sociedade e as vozes dessas posiçóes marginais que, na medida em que transgridem as normas da vida social, assumem o risco da incomunicação e da excentricidade.

As escrituras de Libertella e Eltit podem ser pensadas sob a figura da idiorritmia não apenas porque a ilegibilidade que elas comportam as coloca sob a ameaça da incomunicação e da excentricidade, mas porque encontram sua razão de ser em um traçado transgressivo da letra que abre linhas de fuga que corroem as normas do comunicável e impulsionam a palavra para um exterior da ordem estabelecida da literatura. Em outros termos, pensadas sob o regime de idiorritmia, essas escrituras ilegíveis, que resistem às formas comunicativas de transmissão, problematizam os vínculos com o institucionalizado como literário. Não obstante, cabe perguntar qual é a relação que essas escrituras estabelecem com a comunidade literária quando exploram as

obstáculos. Obstáculos legítimos, agrego, obstáculos que le pertenecen como resultado de un modo de escribir que debe dejar el resuello del pensamiento en el lenguaje" (GONZÁLEZ, 1990: 29).

${ }^{3}$ Neste breve comentário sobre a "fantasia de idiorritmia" que Barthes desenvolve no seu curso, retomo as aulas "Presentaçáo" de 12 de janeiro de 1977 e "Marginalidades" de 23 de março de 1977 (BARTHES, 2013). 
possibilidades do ensaio como forma discursiva que supóe não apenas uma indagação do sujeito, senão também um modo peculiar de indagar o mundo e de dialogar com o outro.

Tal como o definiu Montaigne, ao dizer que seus escritos não comportavam a exposição de um saber senão, sobretudo, um estudo de si mesmo, o ensaio se configura a partir de uma enunciação subjetiva que se interroga em um gesto de descentramento que invalida a plenitude do cogito cartesiano. Nesse sentido, a escritura do ensaio prescinde de regras dedutivas e do delineamento de sistemas e se oferece como um movimento de deriva que carece de ordem e de limites, que dissolve as pautas retóricas e os limites conceituais dos diversos campos do saber e que renuncia à definição de um significado último, vale dizer, de uma verdade unívoca acerca da experiência do mundo. Como explica Nicolás Rosa, o trabalho sobre a linguagem permeia o ensaio, tornando-se evidente na inscrição do estilo do autor e de uma vontade de forma em um texto que possui a sua própria intransitividade. Todo ensaio, adverte esse autor, faz emergir de uma experiência de escritura "algo más que lo que dice cuando dice algo" (ROSA, 2003: 16). Não é casual, portanto, que essa forma discursiva se ofereça como espaço de exploraçáo para escrituras idiorrítmicas que inscrevem na língua uma dinâmica de permanente desequilíbrio e resistem, assim, à transparência da comunicação e à clausura do sentido único.

Atendendo a esse gesto autorreflexivo, Liliana Weimberg assinala que o ensaísta "al tiempo que apela a las palabras de todos, obliga muchas veces al lector a plegarse a sus propias marchas intelectuales, a asomarse a la intimidad de los procesos mentales y sentimentales que implica el enlace entre la experiencia privada con el sentido del mundo" (WEIMBERG, 2006: 27). Entretanto, Weimberg destaca que esse movimento de falar para si mesmo, no qual se inscreve a interpretação de uma experiência de mundo, realiza-se com "las palabras de todos". O ensaio, diz essa autora, "oscila entre la soledad y la sociabilidad" e, nessa oscilação, tornam-se visíveis os traços que o caracterizam, a saber: a busca de uma comunidade que impulsiona a escritura, a responsabilidade que se assume perante a própria palavra (a boa-fé de Montaigne) e a certificação nominal dessa palavra que fornece a assinatura. Seriam esses traços específicos do ensaio os que remetem a uma nova condição de diálogo e debate na cena literária. ${ }^{4}$

\footnotetext{
${ }^{4}$ Weimberg afirma acerca do ensaio: "El acuerdo entre autor, mundo, palabra, lector; el acuerdo entre la tarea de interpretación del mundo que el ensayista desencadena, la versión del sentido interpretado a través de un libro y la participación del acto interpretativo con el lector, son condición necesaria del ensayo. Una obra que es a la vez ergon y energeia; una interpretación del mundo ofrecida desde la propia situación y acto interpretativo permanentemente desencadenado por un hacedor y transmisor de sentido; un nuevo tipo de texto que se convierte a la vez en ventana,
} 
Ante essa caracterização e sem perder de vista que essa forma discursiva trabalha em favor de uma produção de sentido ilimitada e plural, isto é, sem referência universal, coloco a pergunta: que relação se estabelece entre a idiorritmia das escrituras de Libertella e Eltit e a comunidade que o ensaio convoca? Vale dizer, em que medida, ao explorarem o espaço discursivo do ensaio, esses escritores recuperam a enunciação subjetiva ante uma fala neutra, assumem a responsabilidade pela própria palavra antes liberada ao jogo do significante e realizam um exercício interpretativo do mundo e de si mesmos que exige o abandono um uso asignificante da língua?

Quero me limitar a uma questáo específica presente nos ensaios desses escritores: a indagação sobre a prática literária na sua relação com os mandatos de representatividade. Parafraseando mais uma vez Sarduy, trata-se de indagar como os ensaios de Libertella e Eltit desordenam, reviram e dilapidam as sacras arcas da literatura em espanhol.

\section{Pedras encofradas}

A escritura de Libertella avança sobre a literatura dissolvendo as distinções entre o ensaio, a crítica literária e a ficção. Ela extrapola os limites de seus breves e numerosos livros em uma prática do fragmento que opera por recorrência e justaposição, alimentando-se dessa indistinção discursiva. Entre a escrita e a leitura, entre a ficção e a reflexão, a "literatura crítica" de Libertella corrói as pautas de gênero e se estende como "una red dormida de inconsciente y asociación de lecturas" (LIBERTELLA, 1998: 15). Não obstante, é possível reconhecer nesse espaço de indeterminação um gesto reflexivo que interroga a prática da escritura náo apenas naquilo que o ofício de traçar letras comporta, mas também em função da localização dessa prática. A questão focaliza-se especialmente em Nueva escritura latinoamericana (1977) e reaparece, de maneira intermitente, porém com insistência em outros títulos, Ensayos o prueba sobre una red hermética (1990), Las sagradas escrituras (1993), La librería argentina (2003). A biblioteca da América Latina passa, assim, por um peculiar processamento de escritura que não esconde sua obsessão pela materialidade da letra e se detém com irresistível atração no trabalho sobre a língua e o estilo que levam adiante os outros autores. Trata-se de um modo de ler que privilegia o corte, a sincronia e as singularidades expressivas, mas que não deixa de indagar a literatura como prática que se realiza em uma localização específica.

pintura y espejo; transparencia, opacidad y autorreflexión, se apoya así en esta regla básica de todo acuerdo, a la vez jurídico, político, social, cultural, estético, vital: el pronunciamiento de la buena fe" (WEIMBERG, 2001: 18). 
Como assinala Maximiliano Crespi, a nota de leitura é a unidade mínima do ensaio de Libertella. Essas notas têm um caráter incidental e a voz que acolhe esse incidente é uma voz episódica, "un habla casi sin contorno" (CRESPI, 2010: 111), que dissemina os temas em uma estrutura aberta, em um movimento sempre inconcluso. Como toda escritura ensaística, a de Libertella desenvolve-se também como uma prática do inacabado, mas em virtude dessa voz episódica que Crespi descreve de maneira perspicaz como "un habla casi sin contorno", essas notas de leitura distanciam-se das pautas discursivas do ensaio. Elas aproximam-se de uma fala neutra que desestabiliza a enunciação subjetiva característica do gênero.

Uma das figuras que Barthes convoca para representar o neutro é a da vacância da "pessoa", não necessariamente a sua anulação - ele esclarece -, mas o fato de ela se tornar ilocalizável (cf. BARTHES: 2003: 149). Com efeito, falar em neutro, explicava Blanchot, não significa falar em terceira pessoa ou se abrigar em uma expressão impessoal, antes, leva a pensar na destituição do sujeito e na desapropriação de toda ação transitiva (cf. BLANCHOT, 2010: 147-148). A fala neutra, portanto, instaura um movimento de despersonalização que arremessa a palavra para a vertigem de uma interlocução interrompida que a expóe, como explica Roberto Esposito (2009: 188), "a su irremediable pérdida de dominio". Nesse sentido, é possível pensar que, ao se despojar da prerrogativa de dizer "eu", a voz das notas de leitura de Libertella interfere na estrutura dialógica do ensaio para se posicionar em uma perspectiva exterior que possibilita a objetivação da literatura como prática neutral e inscrição incessante de signos. ${ }^{5}$

Essa é a perspectiva que se assume no livro Nueva escritura en Latinoamérica, no qual a literatura é abordada como prática localizada, isto é, posicionada estrategicamente na cartografia do Ocidente, não como discurso que veicula os supostos valores de uma essência latino-americana, mas como escritura que desenha seu próprio território: "la geografía como una suma de inscripciones" (LIBERTELLA, 1977: 11). Busca-se, assim, afastar o

\footnotetext{
${ }^{5}$ Ao abordar a noção do neutro de Blanchot, Esposito afirma que este escritor deu um passo além no processo de desconstrução da relação eu-tu iniciada por Lévinas e questionou a própria estrutura dialógica em favor do que Blanchot definiu como uma "relação de terceiro gênero". Esposito explica que: "Si debe entenderse por primer género la operación dialéctica que atrae al otro a la órbita propia, y por segundo, la unidad inmediata de ambos a la manera de una participación directa, el tercer género está constituido por el vértigo, la interrupción, que se instala entre ambos interlocutores impidiéndoles toda reciprocidad. En este caso ya no está en juego una diversidad de estatus que privilegie a uno en comparación con el otro, o una superioridad que amarre al primero a la palabra magistral del segundo, sino un cambio de perspectiva que afecta a todo el campo lógico y lingüístico, comparable al cambio de paradigma que llevó de la geometría euclidiana a la de Riemann: ya no se definirá la relación según el número de sus términos, pues ya ninguno de estos será un 'término' dotado de la prerrogativa subjetiva de decir 'yo', de hablar en primera persona" (ESPOSITO, 2009: 183).
} 
risco de ideologização da literatura da América Latina e desmarcá-la dos sentidos já dados que os mandatos estéticos do Ocidente projetam sobre ela. Nesse sentido, explica Libertella,

La misma tradición europea pasará a ser concebida como mediata - ajena para que Latinoamérica pueda distanciarse de todo arquetipo y actualizar su problemática in situ: sin negar aquella red geográfica del Continente, y sin pretender un universalismo abstracto que impida internalizarse en los recursos materiales - lengua, palabra, estilos - de una tradición inmediata - propia. (LIBERTELLA, 1977: 20)

Em virtude dessa posição crítica, a leitura de Libertella reconhece na matéria de algumas escrituras um trabalho de "distinta cualidad comunicativa" que permite conceber seus textos como "fijeza última", isto é, como "piedras encofradas que viven ajenas a un dogma social de comunicación, y que valen por una presencia tenaz y deliberada que las explica" (LIBERTELLA, 1977: 27). Suas notas de leitura expóem uma galeria de escrituras que dão corpo a essa ideia e permitem delinear uma tradição própria. Desfilam por elas o balbucio obsessivo de Osvaldo Lamborghini em Sebregondi retrocede, o travestismo enunciativo de Cobra de Severo Sarduy, a dispersa e abúlica enunciação das Prosas apátridas de Julio Ramón Ribeyro, a palavra gozosa de Reynaldo Arenas, a narração em fuga de Umbral, o romance impossível de Juan Emar, o signo parco e retraído do "concentrado salvaje" da narrativa de Juan Rulfo. ${ }^{6}$ Libertella lê essas escrituras como práticas discursivas que resistem a formas sociais de comunicabilidade e que, portanto, só podem ser abordadas em função de suas singularidades expressivas. ${ }^{7}$ No entanto, essas escrituras idiorrítmicas, na sua "fijeza última", na sua condição de "piedras encofradas", não deixam de estabelecer elos com a comunidade, de tecer a rede geográfica de uma tradição própria, mas fazem isso em um jogo de articulação de singularidades que, como explica Jean-Luc Nancy, leva a uma maneira de ser-junto que não remete ao coletivo, e sim a uma partilha das distâncias pela qual "no

\footnotetext{
${ }^{6}$ Remeto às notas de leitura do livro Las sagradas escrituras, publicado em 1993, vários anos depois de Nueva escritura en Latinoamérica, mas nas quais o modo de escrever a leitura sustenta as posições explicitadas no livro de 1977. Nessas notas, Libertella busca reconhecer a forma singular em que determinadas escrituras trabalham, sempre no sentido de resistir aos "usos sociales de la literatura". Cf. "Osvaldo Lamborghini. Procesamiento y residuo" (p. 133-136); "Julio Ramón Ribeyro o la narrativa en su condición migratoria" (p. 137-140); "Reynaldo Arenas: una aventura en el género" (p. 141-144), "Severo Sarduy, una pintura del yo" (p. 150-152); "Juan Emar" (p. 153-161); “Juan Rulfo o el pensamiento literal” (p. 166-169).

${ }^{7}$ A singularidade, entendida nos termos em que a explica de Jean-Luc Nancy em La comunidad desobrada, "no tiene nunca ni la naturaleza ni la estructura de la individualidad. La singularidad no tiene lugar en el orden de los átomos, identidades identificables por no decir idénticas, sino que tiene lugar en el plano del clinamen, inidentificable. Está asociada al éxtasis: no podría decirse con propiedad que el ser singular es el sujeto del éxtasis, porque éste no tiene 'sujeto', sino que debe decirse que el éxtasis (la comunidad) le acaece al ser singular” (NANCY, 2001: 22).
} 
hay más singularidad que la expuesta en común, y no hay más comunidad que la ofrecida en el límite de las singularidades". ${ }^{8}$

Esse modo de ler, assim como a enunciação próxima da fala neutra que se assume para escrever a leitura visam a desmantelar a ideia de uma literatura latino-americana como totalidade orgânica e representativa. Não se trata de se debruçar sobre o corpo histórico da literatura, diz Libertella, e sim de buscar

[...] por detrás, un sistema de lectura que se complique con todos los textos, de modo que en su propia superficie pueda leerse el circuito de fantasías, deliberación y apuestas con que se comunicaron unos practicantes con otros: el deseo, en fin, frente a la propia práctica, esta vez en su viaje errante por el campo de la tradición. (LIBERTELLA, 1977: 50)

Desse modo, a literatura náo se reduz a "un lenguaje dado y recopilable", carregada de significados históricos, nem se limita à "omnipotencia de los tonos personales", antes, ela oferece-se como uma comunidade que tem lugar sempre por meio do outro e para o outro em uma prática incessante de escritura que, na inscrição do traço, busca criar, como sugere Libertella, "las nervaduras de una lengua común" (LIBERTELLA, 1977: 14).

\section{Escrituras em fuga}

Retomo a figura da idiorritmia para caracterizar a escritura de Eltit como movimento intersticial ou posição exorbitante que recusa sua incorporação à literatura como totalidade representativa e estrutura de poder. Embora seus ensaios assumam a forma clássica do gênero e, nesse aspecto, se aproximem de pautas sociais de inteligibilidade discursiva, Eltit náo deixa de convocar a comunidade literária sob um regime de marginalidade que questiona as normas da vida social. A ilegibilidade que permeia suas ficçóes projeta-se no ensaio em perspectivas críticas que questionam os códigos sociais disciplinadores e as instâncias de poder que os sustentam. Como assinala Leónidas Morales, esses textos de Eltit pensam a literatura com base em um entrecruzamento crítico de escritura, corpo e política, isto é, "como materialidad significante, portadora de significados nunca ajenos y siempre 'orientados' desde el punto

\footnotetext{
8 "Por sí misma" - explica Jean-Luc Nancy - "la articulación no es más que la juntura o, más exactamente, el juego de la juntura: lo que tiene lugar allí donde piezas diferentes se tocan sin confundirse, donde se deslizan, pivotan o basculan una sobre otra, una en el límite de otra exactamente en su límite -, allí donde estas piezas singulares y distintas se pliegan o enderezan, se doblan o estiran conjuntamente y una a través de otra, una en la otra misma, sin que este juego mutuo - que sigue siendo sin cesar, al mismo tiempo, un juego entre ellas - forme la sustancia y la potencia superior de un Todo. Pero aquí la totalidad misma es el juego de las articulaciones. Por ello, un todo de singularidades, que ciertamente es un todo, no se vuelve a cerrar sobre ellas para elevarlas a su potencia: este todo es esencialmente la abertura de las singularidades en sus articulaciones, el trazado y el latido de sus límites" (NANCY, 2001: 141).
} 
de vista de las sutiles dialécticas detrás de las cuales se juegan las alternativas y las inflexiones del poder" (MORALES, 2000: 13). Em outras palavras, quando se desloca para o ensaio, a escritura de Eltit busca desmantelar os dispositivos sociais que disciplinam os corpos e os submetem a uma estrutura de poder, mas não deixa de lembrar que, para potenciar qualquer questionamento, a escritura deve se tornar intensiva e que, portanto, "el punto crítico y teórico consistiría en seguir manteniendo la pregunta en torno al lenguaje y sus fronteras" (MORALES, 2000: 39-40).

Essa indagação crítica não se exime da pergunta sobre a literatura da América Latina, ao contrário, esta é interrogada como campo discursivo onde se disputam posiçóes de poder e se desenham linhas de fuga que as questionam. É nesse sentido que Eltit recupera, em um texto de 2007, o inflamado debate acerca da posição do escritor latino-americano que José María Arguedas e Julio Cortázar protagonizaram nos anos 1960. A autora afirma que o que estava em jogo nessa controvérsia era "el poder de la palabra cultural del escritor, una posición de poder para definir ese otro territorio, la construcción del mapa de control social y político que puede alcanzar la literatura, su resonancia” (ELTIT, 2007: 14). ${ }^{9}$ As posiçôes extremas de localismo e cosmopolitismo que se digladiavam na polêmica e que - adverte Eltit - diziam respeito tanto ao lugar concreto como à posição simbólica desde a qual se gestava a letra, parecem ter perdido vigência no contexto globalizado em que a literatura circula atualmente. Para a autora, as redes transnacionais que a expansão do mercado delineou nas últimas décadas impuseram uma condição de trânsito para a escritura que leva a pensar em outras configuraçóes do território literário.

A reflexão, portanto, busca interrogar a própria prática em função da experiência da viagem. Indagação que ressoa na pergunta que dá título ao texto, “¿Qué eres?”. Pergunta ante a qual Eltit se sente interpelada cada vez que cruza fronteiras. A resposta vem das margens: "provinciana" e "escritora", ela diz, localizando sua letra fora da órbita de poder de um sistema literário centrado no cosmopolita e no masculino. Porém, a reflexão ensaística de Eltit não se satisfaz com a resposta que parece surgir rápida e certeira, por isso ela retorna sobre o próprio pensamento para indagar os alcances semânticos desses termos que resultam insuficientes:

Viajo como escritora. Sí. Pero ¿̨ué es eso? ¿Qué significa viajar como escritora? ¿No es ese, acaso, un viaje perpetuo sujeto a fronteras que resultan infranqueables? Pienso que sí, en un sentido, sí. Provinciana no significa provinciano, significa literalmente provinciana, habitante de una provincia cuya localización

\footnotetext{
${ }^{9} \mathrm{O}$ texto intitula-se "¿Qué eres?" e foi publicado pela primeira vez em Provisoria-mente: textos para Diamela Eltit, organizado por Antonio Gómez (2007). Posteriormente foi incorporado ao livro de ensaios de Eltit, Signos vitales: escritos sobre literatura, arte y politica (2008).
} 
es eminentemente cultural. [...] me refiero a la pregunta recurrente y hasta cierto punto monótona sobre la frontera que significa ser escritora. Su ultra localismo, su - se podría decir - provincianismo. (ELTIT, 2007: 16)

O provincianismo de Eltit não se reduz a um pertencimento geográfico, esse sentido é questionado e alargado em função de uma experiência da escritura que se figura como uma viagem perpétua sempre sujeita a atravessar fronteiras. Da mesma maneira, nesse vaivém que permeia a enunciação ensaística da autora, a condição de "escritora" que se alega como via de entrada na literatura também é problematizada. Por certo, essa condição não pode se reduzir a uma simples identificação entre o sexo e a letra, no entanto, ela carrega um potencial subversivo que é conveniente não desprezar quando se deseja apontar lógicas sociais de exclusão:

Pero ¿qué digo cuando digo escritora? ¿Y por qué digo escritora si es un título inexistente? Escribir es escribir, un oficio, una acción artesanal, un trazado. [...] Escritora significa mujer que escribe, significa el ingreso de su sexo y su sexo se funde y se confunde biológico a la escritura con la misma fuerza que porta el signo, y es posible que con un énfasis mayor que el poder de la letra. El órgano se hace letra. (ELTIT, 2007: 18)

Artesã, provinciana, escritora; essa condição - na qual ainda parece ecoar a resposta de Arguedas a Cortázar - sinaliza uma disfunção da prática da escritura que a coloca à margem das engrenagens da produtividade do mercado e fora da órbita de poder do sistema literário que replica as coerções da normatividade social. ${ }^{10}$

Os ensaios de leitura de Eltit também indicam deslocamentos divergentes ao convocar escrituras que, na sua idiorritmia, perturbam os códigos de legitimação da literatura e as lógicas que a organizam como mapa de controle político e social. A leitura que Eltit realiza da poética experimental de Francisco Casas em "La plenitud de la apariencia", na qual ecoam os nomes de Manuel Puig, Reynaldo Arenas e Pedro Lemebel, traz à cena literária os usos políticos do corpo que, em um jogo de dissociação do gênero e do orgânico, desmontam as representaçóes socialmente regulamentadas e propóem outra comunidade possível, "desviada, fragmentaria, corporal, estructurada en la pose, el delirio, la simulación y la máscara” (ELTIT, 2008: 153). Outras leituras insistem em trânsitos que desordenam as marcas de pertencimento, tal como a escritura de Margo Glanz, "cuya constante es el límite” - diz Eltit em "La palabra desmarcada" - "la frontera difusa entre géneros literarios, entre un

\footnotetext{
${ }^{10}$ Nelly Richard refere-se nesses termos às práticas do CADA (Colectivo de Acciones de Arte), do qual Eltit fazia parte no início dos anos 1980, como "un arte de la disfuncionalidad encargado de manifestar esa explosiva persecución de un 'fuera de marco' que consagre su reticencia a la integración normativa" (RICHARD, 1989: 30).
} 
saber internacional y un acontecer 'sabio' latinoamericano entre una tradición sacralizada - susceptible de ser interrogada - y una modernidad que cita 'lo mismo' y, a la vez, desarticula antiguas operaciones textuales" (ELTIT, 2002: 134). A excentricidade de Juan Emar também não se subtrai desse território da letra delineado pelas leituras de Eltit. No ensaio "Emar y la casa de la escritura”, a empresa impossível de Umbral, o livro que se perdeu nos meandros de uma escrita infinita, oferece a imagem mais próxima da própria prática:

Juan Emar en su última vuelta al país no tuvo una casa, digamos, autónoma: se parapetó en el espacio estratégico del umbral - riesgo y borde -, en ese lugar ambiguo que marca tanto un afuera como un adentro o un 'entre' el afuera y el adentro. Y esa posición quizás es la más productiva para establecer una escritura, la más privilegiada y fructífera. (ELTI, 2008: 147)

$\mathrm{O}$ traço incessante da escritura de Emar, o deslocamento limítrofe que desordena os arquivos de Glanz, o travestismo político que desestabiliza identidades de Casas servem como referências para imaginar o comum que convoca o ensaio de Eltit. Uma comunidade, não de organização, nem sujeita a programas, mas de articulação de singularidades expressivas que se abrem ao diálogo. Um diálogo que - como diz Jean-Luc Nancy - "sólo se deja escuchar como la comunicación de la incomunicable singularidad/comunidad. Ahí ya no escucho (ya no esencialmente) lo que el otro quiere decir (me), sino que escucho que el otro, un otro, habla" (NANCY, 2001: 141).

\section{Referências bibliográficas}

BARTHES, Roland. Como viver junto: simulaçóes romanescas de alguns espaços cotidianos. Trad. Leyla Perrone-Moysés. São Paulo: Martins Fontes, 2013.

. Roland Barthes por Roland Barthes. Trad. Leyla Perrone Moysés. Sáo Paulo: Estação Liberdade, 2003.

BLANCHOT, Maurice. A conversa infinita 3: a ausência de livro, o neutro, o fragmentário. Trad. João Moura Jr. São Paulo: Escuta, 2010.

CRESPI, Maximiliano. "El invento de unas ruinas: notas en los márgenes de los ensayos libertellianos". In: DAMIANI, Marcelo (Org.). El efecto Libertella. Rosario: Beatriz Viterbo, 2010.

DELEUZE, Gilles. "Balbuceó..." In: Crítica y clinica. Trad. Thomas Kauf. Barcelona: Anagrama, 1996.

ESPOSITO, Roberto Tercera persona: política de la vida y filosofía de lo impersonal. Trad. Carlo R. Molinari Marotto. Buenos Aires: Amorrortu, 2009.

ELTIT, Diamela. Emergencias: escritos sobre literatura arte y política. Santiago: Ed. Planeta, 2000. . “QQué eres?”. In: GÓMEZ, Antonio (Org.). Provisoria-mente: textos para Diamela Eltit. Rosario: Beatriz Viterbo, 2007. 
. Signos vitales. Escritos sobre literatura, arte y politica. Santiago: Universidad Diego Portales, 2008.

GONZÁLEZ, Horacio. "Elogio del ensayo”, Babel-Revista de Libros, Buenos Aires, n. 18, ago. 1990: 29.

LIBERTELLA, Héctor. Las sagradas escrituras. Buenos Aires: Sudamericana, 1993. . Nueva escritura en Latinoamérica. Caracas: Monte Avila Ed., 1977.

MORALES, Leónidas. El discurso crítico de Diamela Eltit: cuerpo y política. In: ELTIT, Diamela. Emergencias: escritos sobre literatura arte y política. Santiago: Ed. Planeta, 2000.

NANCY, Jean-Luc. La comunidad desobrada. Trad. Pablo Perera. Madrid: Arena Libros, 2001.

RICHARD, Nelly. La estratificación de los márgenes. Santiago: Francisco Zegers Editor, 1989.

ROSA, Nicolás. La sinrazón del ensayo. In: . Historia del ensayo argentino. Buenos Aires: Alianza Ed., 2003.

SARDUY, Severo. Las sacras arcas del español. Antologia. México: FCE, 2000.

WEIMBERG, Liliana. Situación del ensayo. México: Unam, 2006. . El ensayo, entre el paraiso y el infierno. México: FCE, 2001: 18.

Ana Cecilia Olmos é professora Livre Docente de Literatura Hispano-Americana da USP e pesquisadora do CNPq. Gagradou-se na Universidad Nacional de Córdoba (Argentina), fez Mestrado em Teoria Literária na UFSC e Doutorado em Letras na USP. Publicou diversos artigos em revistas especializadas e de difusão cultural e os livros Por que ler Borges (Globo, 2008); Ensayos de narradores (Alción, 2007, em colaboração com Marcelo Casarín) e Em primeira pessoa. Novas abordagens de uma teoria da autobiografía (Annablume, 2009, em colaboração com Helmut Galle et all). E-mail: anaolmos@usp.br 